\author{
RESEARCH ARTICLE \\ 10.1029/2018JB017008 \\ Key Points: \\ - Reaction-induced fracturing of \\ periclase produces self-sustained \\ hydration to brucite \\ - The hydration reaction generates \\ sufficient tensile stress to fracture a \\ confining serpentinite cylinder \\ - Strain localization in the \\ serpentinite includes both tensile \\ and shear components with a power \\ law distribution of shear strain \\ magnitudes
}

Supporting Information:

- Supporting Information S1

- Movie S1

- Movie S2

- Movie S3

- Movie S4

- Movie S5

- Movie S6

- Movie S7

Correspondence to:

$\mathrm{X}$. Zheng,

xiaojiao.zheng@geo.uio.no

Citation:

Zheng, X., Cordonnier, B., McBeck, J., Boller, E., Jamtveit, B., Zhu, W., \& Renard, F. (2019). Mixed-mode strain localization generated by hydration reaction at crustal conditions. Journal of Geophysical Research: Solid Earth, 124. https://doi.org/10.1029/

2018JB017008

Received 9 NOV 2018

Accepted 21 MAR 2019

Accepted article online 5 APR 2019

(C)2019. American Geophysical Union. All Rights Reserved.

\section{Mixed-Mode Strain Localization Generated by Hydration Reaction at Crustal Conditions}

\author{
Xiaojiao Zheng $^{1}$ (D), Benoît Cordonnier ${ }^{1,2}$, Jessica McBeck ${ }^{1}$ (D), Elodie Boller ${ }^{2}$, Bjørn Jamtveit ${ }^{1}$ (D), \\ Wenlu $\mathrm{Zhu}^{3}$ (D), and François Renard ${ }^{1,4}$ (iD) \\ ${ }^{1}$ The Njord Centre, Physics of Geological Processes, Department of Geosciences, University of Oslo, Oslo, Norway, ${ }^{2}$ ESRF \\ - The European Synchrotron, Grenoble, France, ${ }^{3}$ Department of Geology, University of Maryland, College Park, MD, \\ USA, ${ }^{4}$ University Grenoble Alpes, University Savoie Mont Blanc, CNRS, IRD, IFSTTAR, ISTerre, Grenoble, France
}

Abstract Hydration reactions influence rock density and rheology. For example, volume increases produced in hydration reactions may generate sufficient tensile and shear stress to fracture both the rock undergoing the reaction and the surrounding host rock. We performed in situ dynamic X-ray synchrotron microtomography experiments to investigate reaction-induced fracturing. Two experiments on hydration of periclase were performed at 180 or $190^{\circ} \mathrm{C}$, under a confinement of 10 or $80 \mathrm{MPa}$, a pore fluid pressure of 5 or $75 \mathrm{MPa}$, and with or without differential stress. The sample assembly consists of a periclase cylinder inserted into a central hole within a serpentinite cylinder. The reaction from periclase to brucite results in a large volume increase (110\%), pushing the periclase/brucite against the serpentinite and ultimately breaking it. Using time-resolved three-dimensional imaging, we quantify the spatial and temporal distribution of the reaction-induced fractures. We perform digital volume correlation analysis to obtain the incremental strain tensors throughout the hydration and fracturing process. We use numerical models to assess the distribution of stress within the serpentinite. The digital volume correlation results show mixed-mode strain localization. The von Mises strain, indicative of shear, increases by a larger percentage than the contractive or dilatative strain components as the reaction-induced fractures grow. The distribution of von Mises strain follows a power law relationship in the cumulative frequency-magnitude domain, indicative of long-range elastic stress interactions during fracturing. This experimental finding sheds insights on the mechanisms of microseismicity measured in areas undergoing active serpentinization.

\section{Introduction}

Serpentinization of peridotite in the oceanic crust near low-velocity spreading ridges and subduction zones contribute to the Earth's water cycle and influence the rheology of the oceanic and continental lithosphere (Escartin et al., 1997; Guillot et al., 2015; Hirth \& Guillot, 2013; Kelemen \& Hirth, 2012; Malvoisin et al., 2012; O'Hanley, 1992). Porosity, permeability, fluid flux, and reactive surface area determine the extent of reaction because the limiting factor of the reaction is fluid supply (Jamtveit et al., 2008; Kelemen \& Hirth, 2012; Macdonald \& Fyfe, 1985).

Fully serpentinized peridotites are common worldwide, which suggests that fluid pathways remain open, or new pathways are continuously produced during reaction (Macdonald \& Fyfe, 1985; Tutolo et al., 2016). Localized dissolution can contribute to porosity maintenance (Lisabeth et al., 2017; Rouméjon et al., 2015). However, the precipitation of serpentine minerals, due to the transformation of peridotite, may also clog pores, reducing permeability and fluid flow (Andreani et al., 2009; Peuble et al., 2015). Serpentinization reaction produces a solid volume increase of $20-50 \%$. The normal stresses produced in this expansion may fracture surrounding minerals (Iyer et al., 2008; Kelemen \& Hirth, 2012; Macdonald \& Fyfe, 1985; O'Hanley, 1996; Plümper et al., 2012). Such reaction-induced fractures will enhance the rate of hydration by generating new fluid pathways and reactive surface area, thereby providing a positive feedback (Plümper et al., 2012; Rudge et al., 2010; Xing et al., 2018). Field observations, numerical modeling, and ex situ and in situ experimental studies (Iyer et al., 2008; Malvoisin et al., 2017; Rouméjon et al., 2015; Ulven et al., 2014) have found evidence of reaction-induced fracturing during serpentinization. Reaction-induced fracturing is reported to occur in numerous other systems, such as carbonation of olivine (Kelemen \& Hirth, 2012; Kelemen \& Matter, 2008; Lafay et al., 2018; Lambart et al., 2018; Van Noort et al., 2017; Zhu et al., 2016), salt crystallization in cement or building stone (Noiriel et al., 2010; Scherer, 2004), and growth of travertine veins (Gratier et al., 2012). 
a)

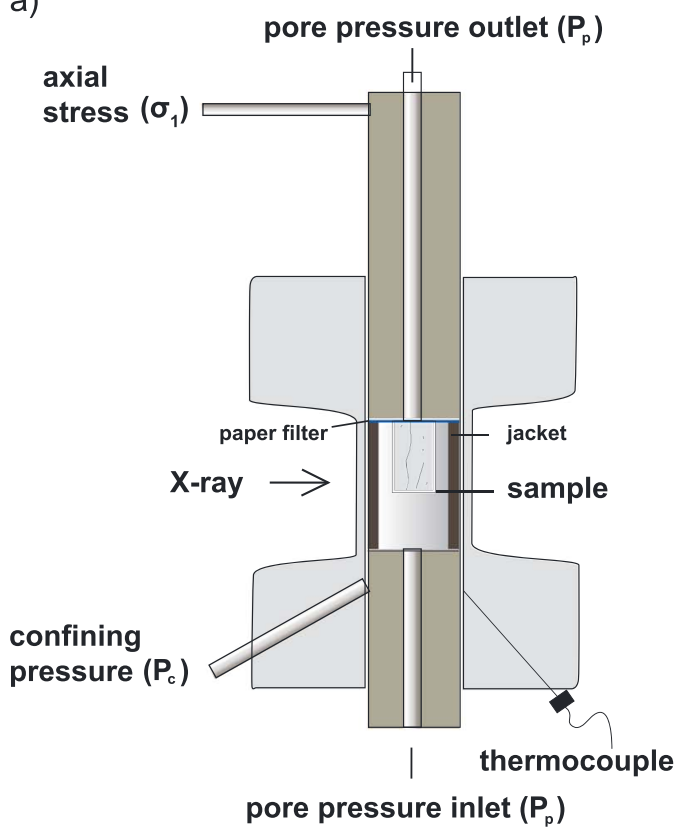

b)

$$
\begin{array}{r}
\mathrm{MgO}+\mathrm{H}_{2} \mathrm{O}=\mathrm{Mg}(\mathrm{OH})_{2} \\
+110 \% \text { volume increase }
\end{array}
$$
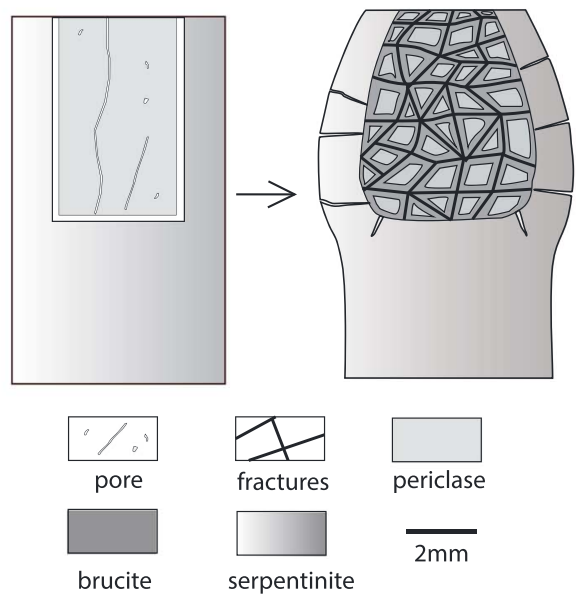

Figure 1. Experimental setup and experimental conditions. (a) Schematic diagram of the HADES triaxial deformation apparatus. (b) Schematic diagram of the hydration reaction associated with the fracturing of both the periclase/brucite and the surrounding serpentinite cylinder.

Schlindwein and Schmid (2016) linked the unusually deep microseismicity observed at a slow-spreading ridge in the Indian Ocean to active serpentinization and fluid circulation at depth. More recently, Horning et al. (2018) showed that hydration reactions may generate microearthquakes in partly serpentinized peridotites at 3-7-km depths. However, the underlying mechanics of serpentinization, and in general, hydration reaction-induced seismicity, are not well understood. Microseismicity observed in the field usually have large shear components. However, the volume expansion during hydration reactions is generally thought to produce opening mode I cracks (e.g., Zhu et al., 2016).

To our knowledge, there is no systematic experimental investigation of the modes of strain localization during hydration reaction-induced failure process. In the present study, we conducted two periclase hydration experiments at 180 or $190{ }^{\circ} \mathrm{C}$, under confinement of 10 or $80 \mathrm{MPa}$, pore fluid pressures of 5 or $75 \mathrm{MPa}$, and with low or high axial stresses. Zheng et al. (2018) showed that as long as the effective mean stress of the system is under $30 \mathrm{MPa}$, the periclase to brucite transformation will proceed to completion within a few hours and produces a volume increase of $110 \%$ (Kuleci et al., 2016). To study the modes of strain localization arising from reaction-induced fracturing, we inserted a periclase cylinder into a drilled hole within a serpentinite cylinder and observed how the serpentinite deformed under the load produced by the transformation of periclase into brucite. The expanding periclase-brucite system exerted sufficient normal stresses on inside of the serpentinite to break it. In the present experimental study, we constrain the rate at which hydration reactions lead to fracturing of the host rock, as well as the evolving contributions of shear and tensile strain during fracturing. Our results provide new insights into the mechanics of microseismicity during active oceanic serpentinization.

\section{Materials and Methods}

\subsection{Sample Preparation}

The serpentinite samples were taken from a block of carbonated serpentinite complex in Linnajavri, Norway (Beinlich et al., 2012). The serpentinite is composed of antigorite, minor dolomite, chromite, magnetite, and accessory talc and tremolite. Two cylinders of 10-mm height and 5-mm diameter were cored. A hole of 5-mm depth and 2.3- or 2.7- $\mathrm{mm}$ diameter was drilled into the serpentinite cylinders (Figure 1). Around the hole, the serpentinite wall thickness was in the range of $1.15-1.35 \mathrm{~mm}$. Inside the hole, a cylinder with 
Table 1

Experimental Conditions for All Samples

\begin{tabular}{lccccccc}
\hline Test & $\sigma_{1}(\mathrm{MPa})$ & $\mathrm{P}_{\mathrm{c}}(\mathrm{MPa})$ & $\mathrm{P}_{\mathrm{p}}(\mathrm{MPa})$ & $\sigma_{\text {eff }}(\mathrm{MPa})$ & $\sigma_{\text {diff. }}(\mathrm{MPa})$ & $\mathrm{T}\left({ }^{\circ} \mathrm{C}\right)$ & $\mathrm{t}(\mathrm{min})$ \\
\hline Sp01 & $30 \rightarrow 25 \rightarrow 50$ & $10 \rightarrow 5$ & 5 & $12 \rightarrow 10 \rightarrow 15$ & $20 \rightarrow 15 \rightarrow 45$ & 180 & 220 \\
Sp02 & 81 & 80 & 75 & 5 & 1 & 0.8 \\
\hline
\end{tabular}

Note. Arrows represent changes of stress states in experiment Sp01 during reaction. $\sigma_{1}=$ axial stress, $\sigma_{2}=\sigma_{3}=\mathrm{P}_{\mathrm{c}}=$ confining pressure, $\mathrm{P}_{\mathrm{p}}=$ pore-fluid pressure, $\sigma_{\text {eff }}=(\sigma 1+2 \sigma 2) / 3-$ Pp effective mean stress, $\sigma_{\text {diff }}=\sigma_{1}-\mathrm{P}_{\mathrm{c}}$ differential stress, $\mathrm{T}=$ temperature, $\mathrm{t}=$ duration of experiment after temperature was stable, and water was injected. $\Phi_{0}=$ initial porosity of periclase core.

dimensions of 2.2-mm diameter and 5-mm height of periclase ceramic, similar to that used in Zheng et al. (2018), was inserted. The preparation technique necessitates a gap $(<0.3 \mathrm{~mm})$ between the periclase core and the serpentine wall and the gap at the bottom of the hole $(<0.7 \mathrm{~mm})$. The microstructure of the periclase and its composition measured by X-ray diffraction are shown in supporting information Figure S1. The periclase ceramic had an initial porosity between $0.8 \%$ and $1.5 \%$, measured at the resolution of the $\mathrm{X}$-ray tomography images (Figure 1). Pores and several small preexisting cracks comprised the initial porosity. The reaction $\mathrm{MgO}+\mathrm{H}_{2} \mathrm{O} \Leftrightarrow \mathrm{Mg}(\mathrm{OH})_{2}$ has an associated solid volume increase of about $110 \%$ accompanying a $45 \%$ increase of solid mass during complete hydration with deionized water (Kuleci et al., 2016).

\subsection{The HADES Deformation Apparatus}

Each sample was placed in the triaxial deformation apparatus HADES (Renard et al., 2016), where the confining pressure, axial stress, pore fluid pressure, and temperature can be controlled independently (Figure 1). A jacket made of Viton fluoropolymer elastomer encased each sample, separating the confining medium (silicon oil) and the pore fluid (distilled water). HADES is almost transparent to X-rays and is mounted on a rotating stage at the X-ray tomography beamline ID19 at the European Synchrotron Radiation Facility in Grenoble, France. Schematic illustrations of the deformation apparatus and the experimental conditions are shown in Figure 1.

The radiographs were acquired with an exposure time of $6 \mathrm{~ms}$, and 2,500 projections were captured as the sample was rotated continuously over $180^{\circ}$. The total acquisition time was $180 \mathrm{~s}$ for each volume. Tomograms were acquired every 2-5 min during the progress of reaction. Two experiments under different stress conditions were conducted. Each run lasted for approximately $6 \mathrm{hr}$. The tomograms were then reconstructed with 16-bit gray level resolution and a voxel size of $6.5 \mu \mathrm{m}$, following the procedure of Zheng et al. (2018).

\subsection{Experimental Conditions}

Two experiments, labeled Sp01 and Sp02, were performed at different confining pressures, $\mathrm{P}_{\mathrm{c}}$, pore pressures, $\mathrm{P}_{\mathrm{p}}$, and axial stresses, $\sigma_{1}$. The main parameter that we varied was the pore fluid pressure with experiment Sp01 performed under low pore pressure and experiment Sp02 performed under high pore pressure (Table 1). A small fluid pressure gradient of $0.5 \mathrm{MPa}$ was imposed between the pore fluid inlet and outlet of the sample to drive fluid flow. In the experiments, the confining pressure and axial load were imposed first, and then the sample was heated at $2{ }^{\circ} \mathrm{C} / \mathrm{min}$ until the desired temperature $\left(180\right.$ or $\left.190{ }^{\circ} \mathrm{C}\right)$, before the pore fluid pressure was increased to the desired value (Figure 2). We did not observe damage created during the heating step. For experiment Sp01, we changed the loading conditions because the periclase had started to react and expand upward. We therefore increased the axial stress to enable fluid flow to the periclase/brucite. This loading change produced the strain was detected by the digital volume correlation (DVC) technique (see section 3.2). The reaction began when the axial stress was $50 \mathrm{MPa}$ and the confining pressure was $10 \mathrm{MPa}$. This experiment was performed under a low fluid pressure of $5 \mathrm{MPa}$. Experiment Sp02 was performed at constant axial stress $(81 \mathrm{MPa})$, confining pressure $(80 \mathrm{MPa})$, and high fluid pressure (75 MPa). All the stresses indicated in Table 1 were imposed by the operators and were not a result of the reaction. For both experiments, we report the origin of time as when the pore fluid pressure was imposed, corresponding to the time when distilled water reached the sample. 

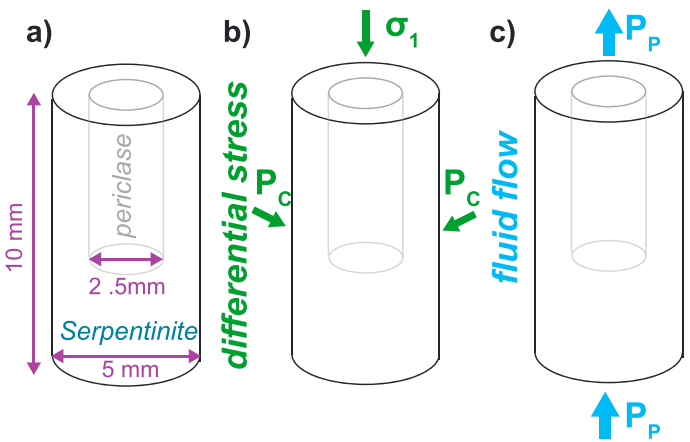

d)

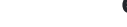

e)

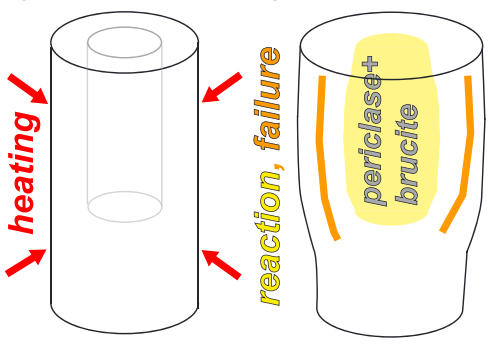

Figure 2. Experimental setup and procedure. (a) A $2.5 \times 5 \mathrm{~mm}$ periclase ceramics core was placed in a $5 \times 10 \mathrm{~mm}$ serpentinite cylinder with a drill hole. (b) The axial and confining pressures were imposed first. (c) A fluid pressure was imposed with a small pressure gradient of $0.5 \mathrm{MPa}$ between the pore fluid inlet and outlet of the sample to drive fluid flow. (d) Then, the sample was heated at $2{ }^{\circ} \mathrm{C} / \mathrm{min}$ until the desired temperature (180 or $\left.190{ }^{\circ} \mathrm{C}\right)$. (e) Schematic representation of the expanded periclase/brucite sample after a period of volume increase due to the formation of brucite with associated fracturing of the serpentinite.

\subsection{Segmentation of Tomograms}

The 3-D tomograms were postprocessed with the software AvizoFire ${ }^{\mathrm{TM}}$. A workflow similar to that in Zheng et al. (2018) was applied. First, a nonlocal means filter was applied to reduce noise (Buades et al., 2005). The two solid parts in the sample, the serpentinite and the periclase, were masked and segmented separately (Figure 3). In order to segment different phases at every time step, we calculated histograms of the gray value frequency distribution from 180 million voxels. Within the periclase cylinder, we measured changes in the volume fraction of periclase, brucite, and pore space. For the serpentinite volume, we segmented the fractures from the solid and calculated the change of the volume and spacing of these fractures as a function of time.

The porosity measured from X-ray tomography (CT) data may be higher than that measured by helium or mercury porosimetry because mercury and helium could only reach connected pore throats (Njiekak et al., 2018). We measured the porosity through the built-in function of Avizo software ("connected component") to acquire the connected porosity in our samples, following the procedure of Zheng et al. (2018). In this case the term "connected" stands for the automatically detected connected volumes, down to a minimum threshold size (set to 1 voxel). Pore voxels are interpreted to be connected in 3-D if they share at least one common voxel face.

\subsection{DVC Analysis}

Following the approach of McBeck et al. (2018) and Renard et al. (2018), we performed DVC analysis to obtain information on the evolution of the displacement field within the serpentinite (Figure 4). Threedimensional DVC analysis was first developed for engineering applications (Bay et al., 1999) and then applied to study of soils (Viggiani et al., 2004) and sandstones (Louis et al., 2007). We used the software Tomowarp2 (Tudisco et al., 2017). DVC analysis searches for the displacements that maximize the correlation between voxel intensity subsets (subvolumes) within pairs of sequential tomograms (Hall et al., 2010; Tudisco et al., 2015, 2017). By identifying similar patterns across successive volumes, DVC analysis produces 3-D displacement fields from which the six independent components of the second rank 3-D strain tensor may be calculated (Figure 4). These incremental strain fields reveal strain localization that occurred within the time interval between the acquisitions of the pair of tomograms. The parameters used in DVC analyses may be tuned to capture contrasts in the X-ray attenuation coefficient fields, such as portions of grains, which can be recognized in successive tomogram pairs. Following systematic tests, we selected a correlation window size of 10 voxels $(65 \mu \mathrm{m})$ and node spacing distance of 20 voxels $(130 \mu \mathrm{m})$. The node spacing controls the spatial resolution of the calculated displacement fields and, consequently, the spatial resolution and magnitude of the components of the strain tensor. This choice ensured that each window contained a subvolume with sufficient contrast to calculate a reliable correlation.

Following McBeck et al. (2018), we report changes in the local volumetric and shear strain fields using the first invariant of the incremental strain tensor, $I_{1}$, and the von Mises yield criterion equivalent 

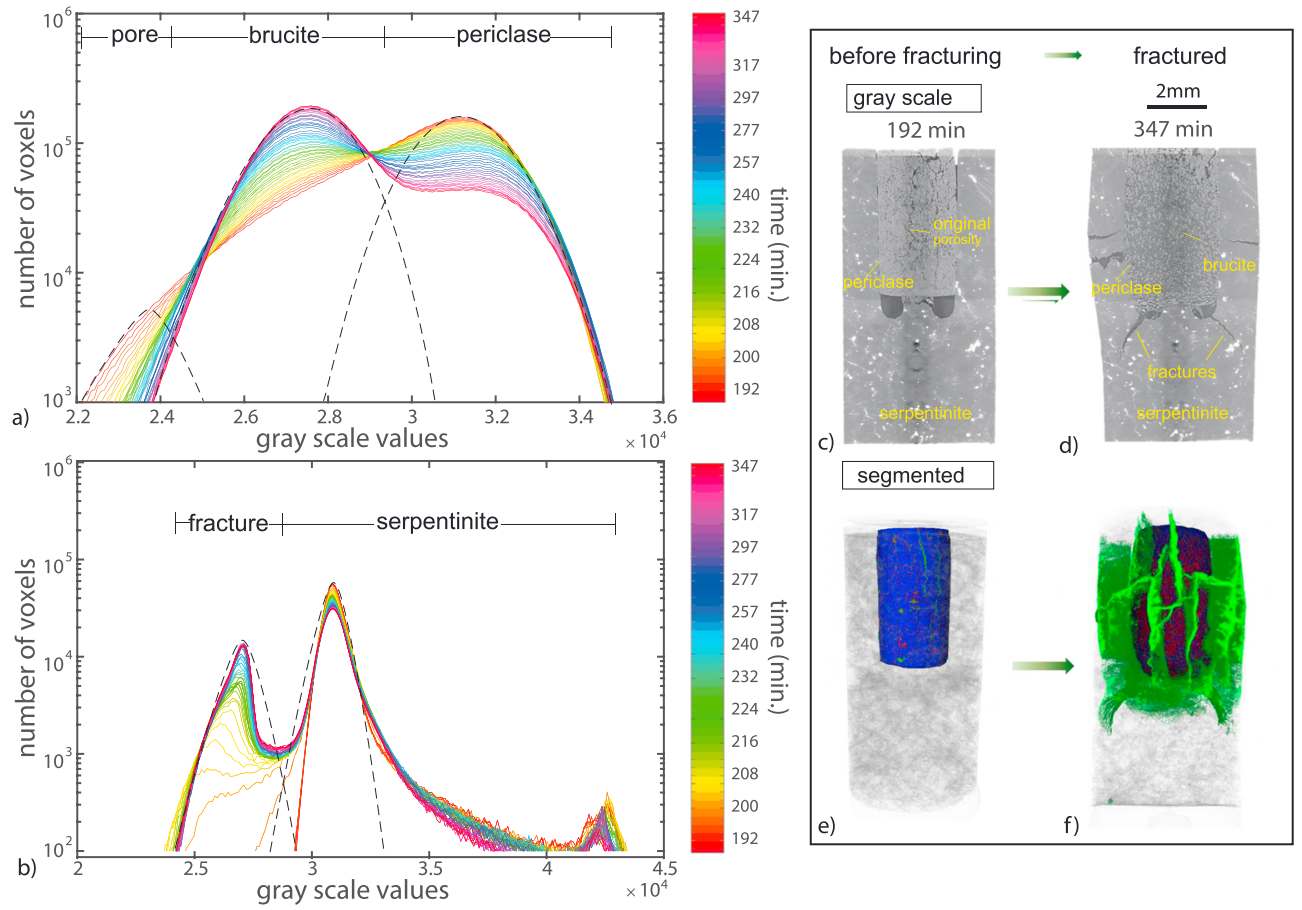

Figure 3. Segmentation of the different mineral phases and void space. (a) Histograms of grayscale values of the periclase cylinder in several microtomograms of sample Sp02 undergoing the periclase to brucite transformation. The histograms (solid curves) can be divided into three overlapping bell-shaped curves (dashed lines), which from small to large grayscale values correspond to pore space, brucite, and periclase. The periclase volume fraction decreased, while the brucite fraction increased with time as the reaction progressed. (b) Histograms of grayscale values of the serpentinite in several microtomograms of sample Sp02 undergoing fracturing. Two bell-shaped curves correspond to the open fractures (lower gray scale) and the serpentinite (higher gray scale). (c) Vertical grayscale slice of a tomogram of sample Sp02 before reaction. (d) Vertical gray scale of a tomogram after reaction and fracturing. (e) Segmented tomogram before the reaction in experiment Sp02. Blue indicates periclase, green indicates porosity, and red indicates brucite. (f) Segmented tomogram at the end of experiment. The 3-D fracture network in the serpentinite is shown in green.

strain, $\left(3 J_{2}\right)^{1 / 2}$, where $J_{2}$ is the second invariant of the incremental strain deviator tensor, $J_{2}=\frac{1}{3} I_{1}{ }^{2}-I_{2}$, and $I_{1}$ and $I_{2}$ are the first and second invariants of the incremental strain tensor, respectively. In the adopted sign convention, negative values of $I_{1}$ indicate net volumetric dilatancy, positive values of $I_{1}$ indicate net volumetric contraction, and $\left(3 J_{2}\right)^{1 / 2}$ is used as a proxy for the magnitude of incremental shear strain. Following previous studies (McBeck et al., 2018; Renard et al., 2018), we kept only incremental strain values above the DVC resolution of $4 \times 10^{-3}$. Below this resolution, calculated DVC strain increments are within the noise of the DVC technique used here.

\subsection{Mechanical Modeling}

To investigate the conditions required to produce tensile failure in the serpentinite, we build 2-D linear elastic mechanical models of horizontal slices of the serpentinite portion of the experiment using the boundary element method code Fric2D (Cooke \& Pollard, 1997). Fric2D solves the quasi-static equations of deformation to determine the displacements and stresses throughout a 2-D plane strain model produced by a given set of boundary conditions (e.g., Cooke \& Pollard, 1997). Boundaries are discretized into linear elements that may translate, rotate, open, or slip in response to tractions or displacements applied to them. Fric2D enables sampling the displacement and stress fields throughout the model produced by the loading conditions. Fric2D is available as part of the GROW package tools available on GitHub.

In the present study, we build models that represent a quarter section of a horizontal slice of the serpentinite cylinder. The radii of the inner and outer concentric circles that define the model boundaries match those of the experiments. The inner circular model boundary represents the boundary between 


\section{scan $n$}
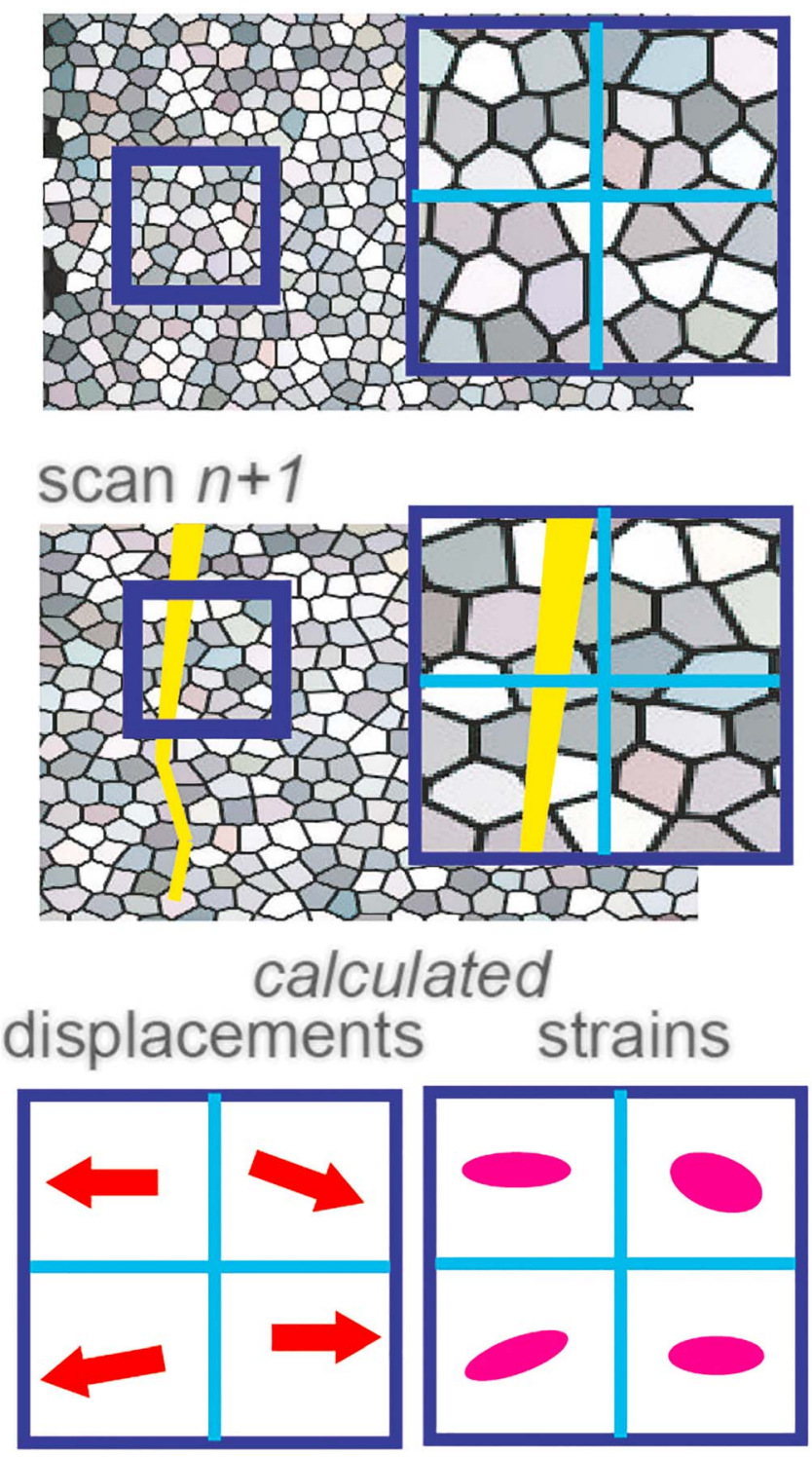

Figure 4. Schematic representation of digital volume correlation analysis This technique estimates incremental displacement fields between tomogram pairs by matching patterns (gray polygons) across successive scans (i.e., scan $n$ and scan $n+1$ ) within subvolumes (light blue squares). Digital volume correlation analysis captures the inelastic and elastic contributions to deformation as fractures (yellow) propagate. The full incremental strain tensor (pink ellipses) can be calculated from the incremental displacement fields (red arrows). the serpentinite and periclase/brucite. The outer circular model boundary represents the boundary between the serpentinite and confining jacket. The planar model boundaries that connect the inner and outer boundaries are free to displace laterally (no shear tractions) and are fixed with no normal displacements. We set the confining stress on the outside of the serpentinite cylinder constant at $20 \mathrm{MPa}$. To constrain the normal stress required to break the serpentinite cylinder, we ran a series of models with different normal stresses exerted on the inner wall. The prescribed elastic modulus (50 GPa) and Poisson's ratio (0.25) are within the range of laboratory measurements of serpentinite (Song et al., 2004).

\section{Results}

\subsection{Phase and Microstructure Evolution}

In this study, the effective mean stress in experiments Sp01 and Sp02 was below $30 \mathrm{MPa}$ (Table 1), and the reaction-induced fracturing was observed within the time scale of the experiments (Zheng et al., 2018). The early stages of the hydration process in the periclase core were consistent with the observations of Zheng et al. (2018). After an initially slow phase (stage 1 ), the replacement of periclase by brucite accelerated, and the periclase core started to fracture (Figure 5). In our previous experiments on the transformation of periclase to brucite, the porosity initially increased but subsequently decreased, generating a "porosity pulse" (Zheng et al., 2018). In the present experiments, however, the porosity (and replacement rate) generation reached a plateau (stage 2) followed by fracturing of the surrounding serpentinite cylinder (Figure 5). After the fracturing of the serpentinite wall, the porosity in the periclase core of experiment Sp01 decreased slightly (stage 3 ). In experiment Sp02, the porosity continued to increase following fracturing and then stabilized.

In experiment Sp01 (Figure 5a and Movie S1), segmentation revealed evidence of brucite after $100 \mathrm{~min}$. At $170 \mathrm{~min}$, the porosity reached a plateau level of about $4.5 \%$. After $220 \mathrm{~min}$, the reaction was about $40 \%$ complete in terms of periclase consumption (Figure S2). The fracturing of the serpentinite wall began at $190 \mathrm{~min}$, producing a slight increase and then decrease in the porosity of the periclase-brucite mixture. For experiment Sp02 (Figures 5b and S2b and Movie S2), brucite was observed after $150 \mathrm{~min}$, and fracturing of serpentinite started after $196 \mathrm{~min}$. At $200 \mathrm{~min}$, the periclase-brucite core reached a maximum porosity of $2.3 \%$. After $340 \mathrm{~min}$, the reaction was about 50\% complete (Figure S2).

During the experiments, the periclase grains fragmented, resulting in a decrease in grain size and an increase in number of distinct grains (Figures $6 \mathrm{a}$ and $6 \mathrm{~b}$ ). At the initiation of the hydration process, there was only one periclase grain with a mean grain size of $5-7 \times 10^{-10} \mathrm{~m}^{3}$. As the reaction progressed, the periclase volume gradually fragmented into smaller grains. At the end of the experiments, several large grains remained because the reactions were only $\sim 40-50 \%$ complete.

\subsection{Fracture Development in the Serpentinite}

The volume expansion associated with the hydration of periclase led to fracturing of the surrounding serpentinite. Fracturing began when the imposed loading conditions were constant and not during changes in differential stress. We analyzed the evolution of this fracture network as a function of time. The expanding periclase cylinder touched the inner wall of the serpentinite at around $160 \mathrm{~min}$. The first cracks initiated 

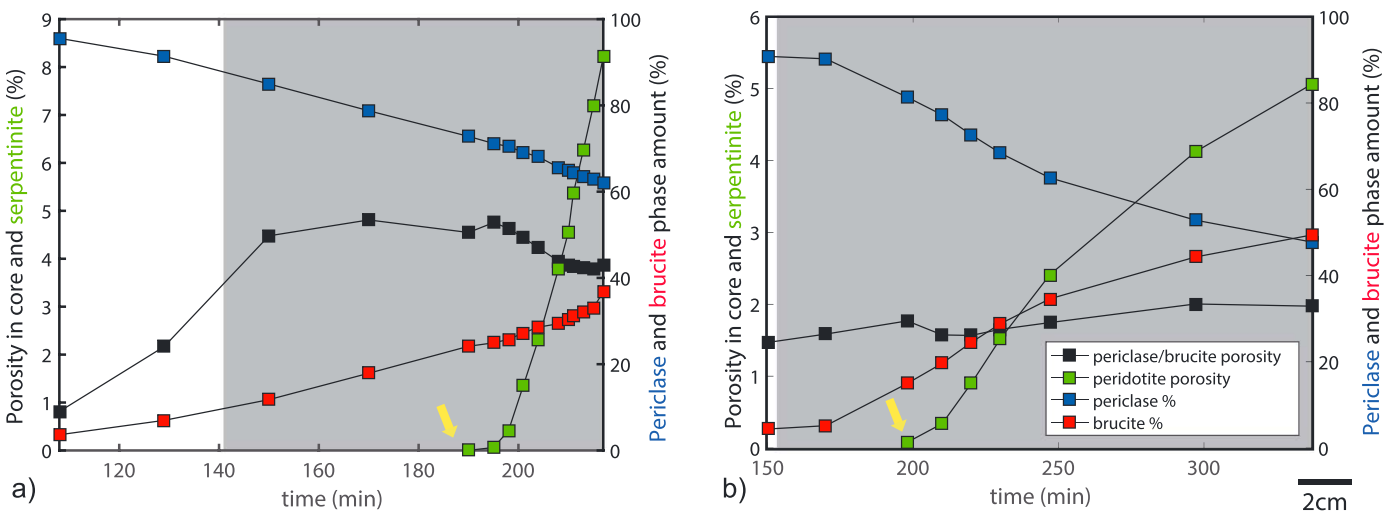

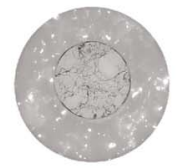

c) $170 \mathrm{~min}$

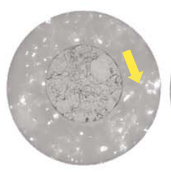

190min

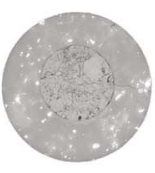

$195 \mathrm{~min}$

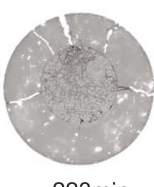

$223 \mathrm{~min}$

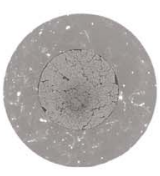

d) $194 \mathrm{~min}$

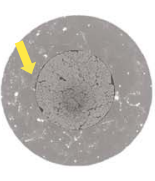

$196 \min$

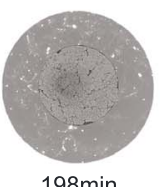

$198 \mathrm{~min}$

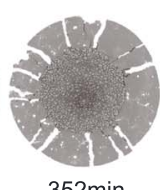

$352 \mathrm{~min}$

Figure 5. Evolution of the volume of periclase (blue), brucite (red), porosity within the periclase/brucite (black), and porosity with the serpentinite (green). (a) Evolution of these phases in experiment Sp01. (b) Evolution of the phases in experiment Sp02. Data are normalized by the maximum value of the corresponding parameter. Gray areas indicate the time windows where the digital volume correlation calculations were performed. (c) 2-D slices showing the phases evolution in experiment Sp01. (d) 2-D slices showing the phases evolution in experiment Sp02. Yellow arrows point to the appearance of the first fracture located for both samples at the inner serpentinite wall.

from inner wall of the serpentinite cylinder in both Sp01 and Sp02 at 190 and 196 min, respectively (Figures $5 \mathrm{c}$ and 5d). The yellow arrows in Figure 5 indicate the moment when we observed the first fractures in each experiment at the voxel resolution of $6.5 \mu \mathrm{m}$ of the tomograms. However, these fractures likely nucleated with apertures smaller than the $6.5-\mu \mathrm{m}$ resolution, and so they likely nucleated earlier. These
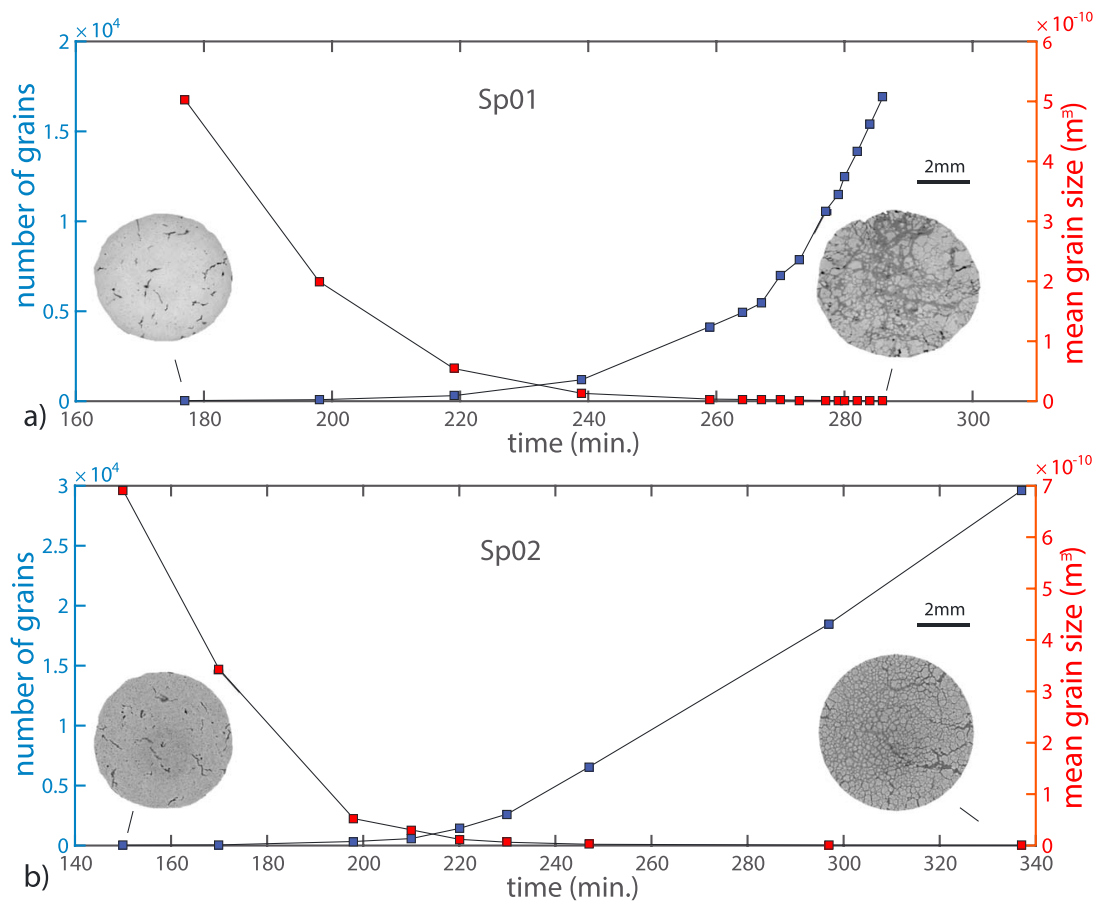

Figure 6. Grain size evolution in the periclase core in experiments Sp01 (a) and Sp02 (b). Blue curve represents the number of grains. Red curve displays the mean grain size at each time step. 


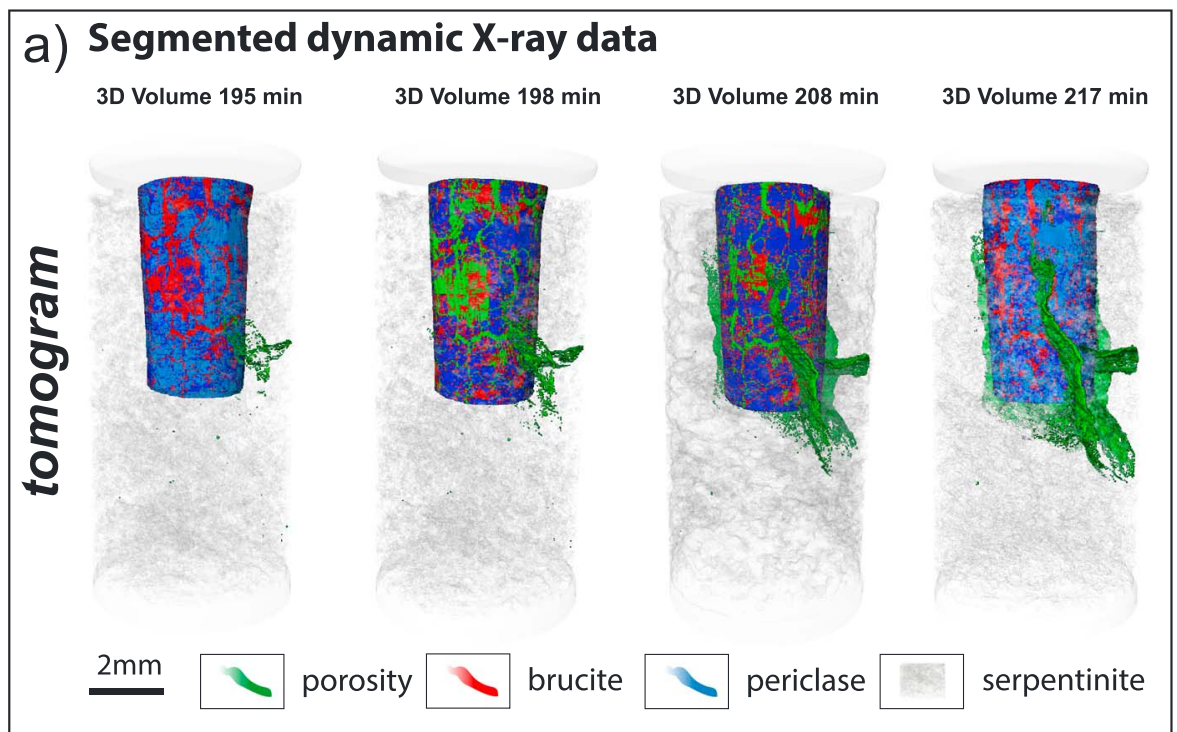

\section{b) Digital volume correlation analysis}
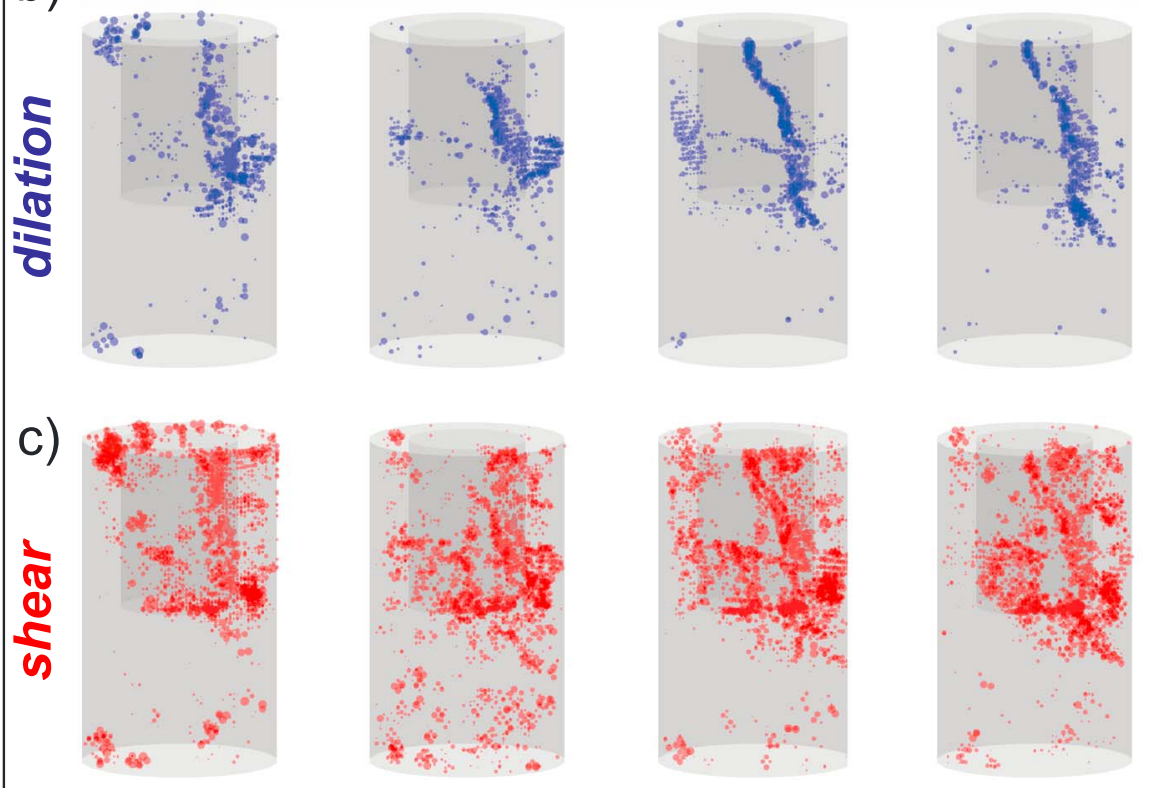

Figure 7. (a) Three-dimensional views of the segmentation of sample Sp01. Green indicates fractures, blue indicates periclase, and red indicates brucite. Digital volume correlation estimates of incremental (b) dilatant (blue) and (c) shear strains (red) above the 90th percentile of the population. The sizes of the dots are proportional to the strain magnitude. Movie S3 shows the complete evolution of these strain components.

fractures grew and coalesced, forming a connected network (Figures 7a and 8a). Most of the fractures opened perpendicular to the core boundary and extended from the periclase/brucite core to the outer wall of the serpentinite (Figures $5 \mathrm{c}, 5 \mathrm{~d}, 7 \mathrm{a}$, and $8 \mathrm{a}$ ). The first fractures nucleated at the inner wall of the serpentinite cylinder (Movies S5 and S6). Then, before $200 \mathrm{~min}$, the fracture apertures were wider near the outer serpentinite perimeter and narrower toward the center because of the circular geometry of the serpentinite cylinder. Then, after $200 \mathrm{~min}$, newly propagating fractures had wider apertures toward the center, except for the existing fractures that continued to widen. After $210 \mathrm{~min}$, the fractures widened and gradually coalesced, forming a 3-D network (Movie S7). Incremental strains calculated through DVC analysis (Figures 7b, 7c, 8b, and 8c) show that fracture development in the serpentinite produced mixed-mode strain localization, with dominantly shear and dilatant components. 

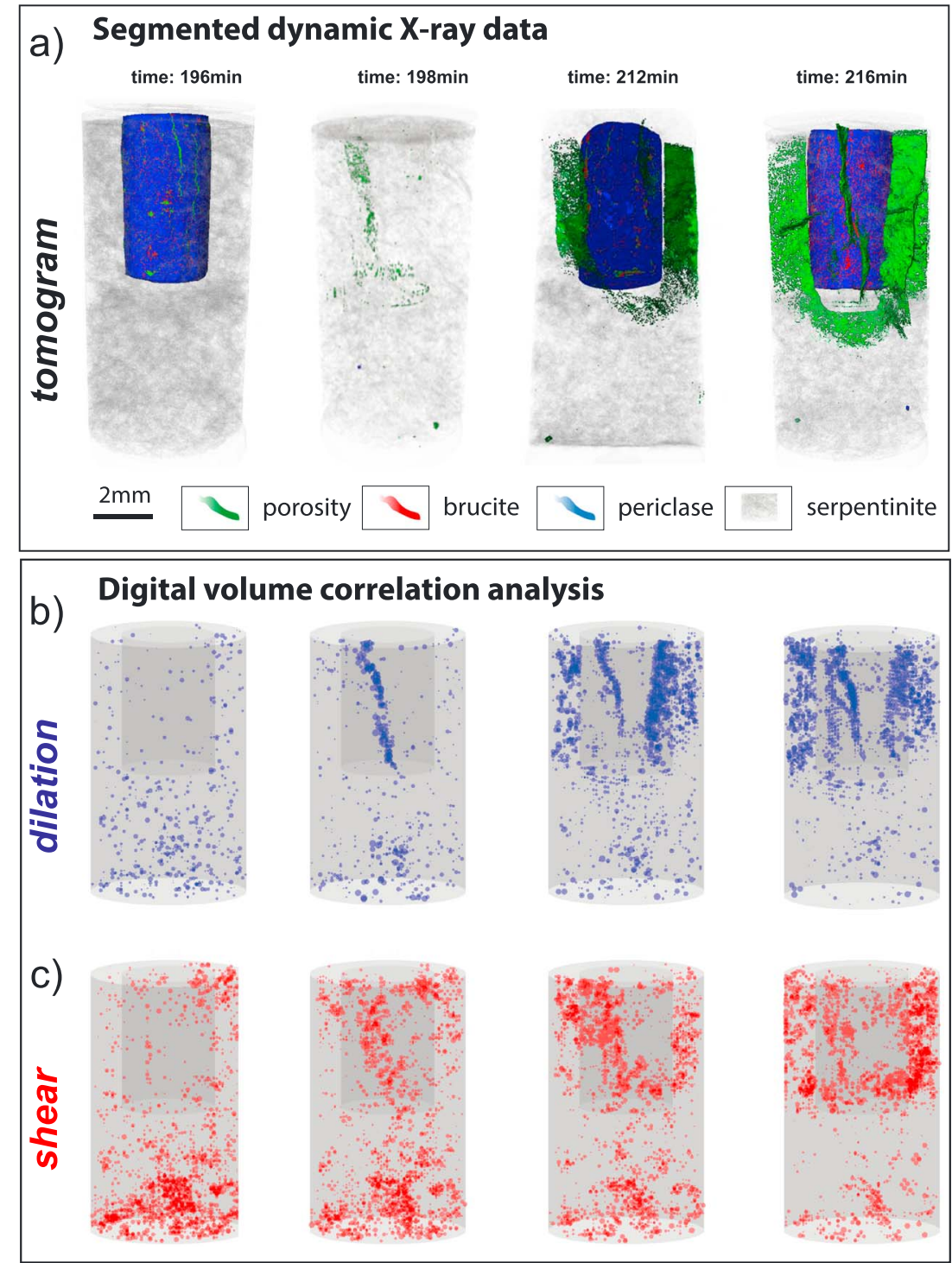

Figure 8. (a) Three-dimensional view of the segmentation of sample Sp02. Note that at time $198 \mathrm{~min}$, the periclase core was masked to show microfractures in the serpentinite more clearly. Green indicates fractures, red indicates brucite, and blue indicates periclase. Digital volume correlation estimates of incremental (b) dilatant and (c) shear strains above the 90th percentile of the population. The sizes of the dots are proportional to the strain magnitude. Movie S4 shows the complete evolution of these strain components.

We calculated the incremental strain components using DVC analysis in both experiments. The incremental dilatant, contraction, and shear strain both increased and decreased during the hydration-induced deformation (Figures 9a and 9b). The increase of normalized incremental strain values from 170-190 min in experiment Sp01 corresponds to a change in loading conditions. The significant increase of incremental contraction, dilatant, and shear strain beginning at 195 min coincides with the first observations of fractures in experiment Sp01. These fractures formed shortly after the loading conditions changed, and the stress on the sample was constant. They were related to the force of crystallization exerted by the transforming periclase core. At around $210 \mathrm{~min}$, the normalized strain components dropped and then became stable as preexisting fracture widened, and few or no new fractures nucleated. As the incremental strain magnitudes decreased, the rate of fracture spacing decreased (Figure 10). For experiment Sp02, the incremental dilatant, contraction, and shear strain also increased after the first observable fracture nucleated. Stabilization of the strain values occurred over a longer time period in experiment Sp02 than Sp01, probably because of the 

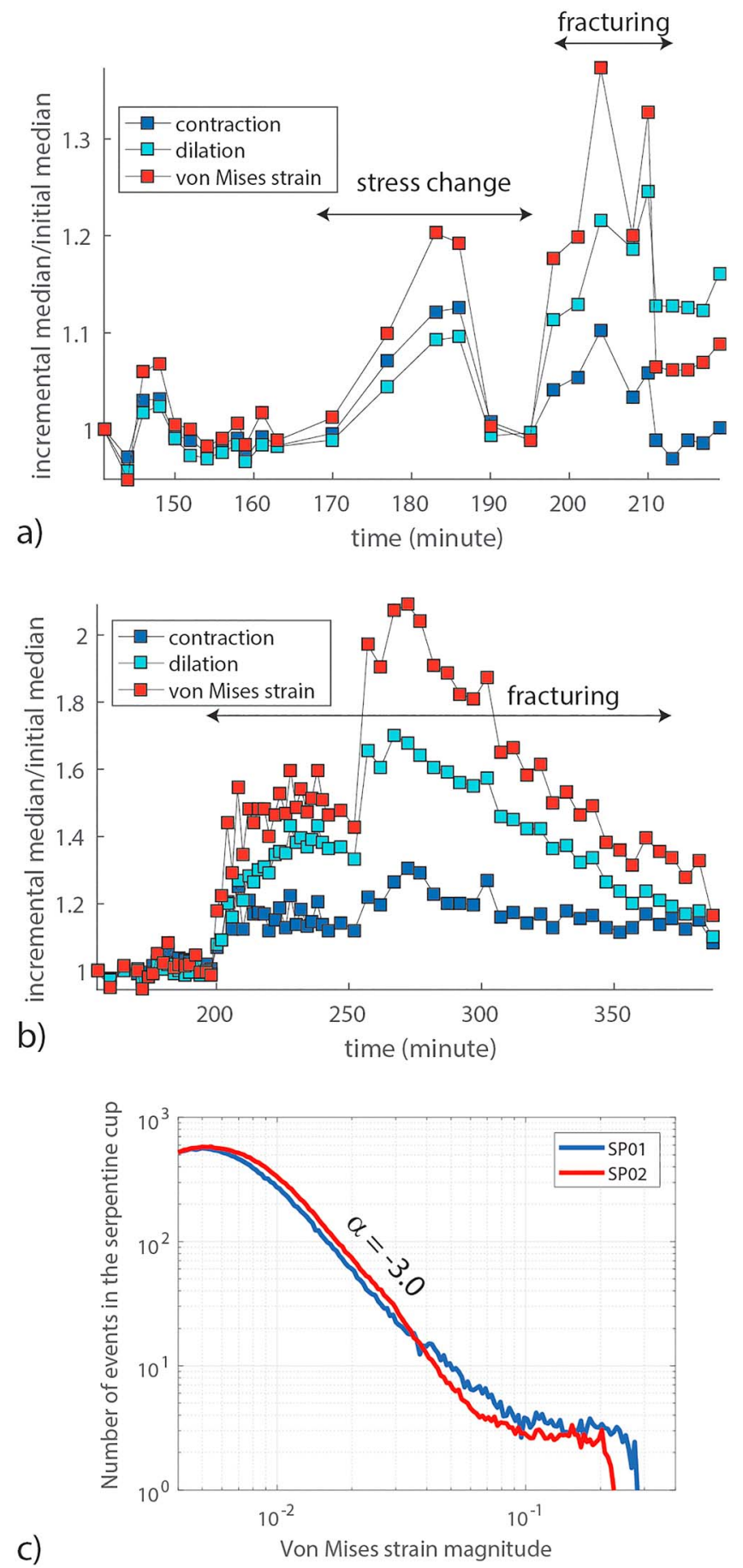

c)

Figure 9. Incremental dilatant, contraction, and von Mises strain in experiments Sp01 (a) and Sp02 (b). Fracturing produces changes in the magnitude of strains. (c) Power law distribution of the magnitude of Von Mises shear strain events in the serpentinite. The slope $\alpha$ has a value of $-3.0 \pm 0.2$. higher fluid pressure in Sp02. The sudden increase around 250 min can be related to the formation of a shear fracture larger than the other fractures (Movie S4). Here the von Mises strain and dilatant components change more than the contraction component.

We analyzed the correlations in strain increment distributions by plotting the distribution of the shear strain increments above a value of $4 \times 10^{-3}$, which corresponds to the resolution of the DVC analyses used here. In a log-log representation, the shear strain increments show a straight-line distribution (Figure 9c), indicating power law scaling over one order of magnitude in incremental shear strains. The slopes of the curves in Figure 9 correspond to the exponent of these power laws and were calculated using a goodness-for-fit method (Clauset et al., 2009). The power law exponent was equal to $3.0 \pm 0.2$ for both experiments. This high value of the exponent indicates that the proportion of small shear strain increments is larger than large ones. This power law also indicates that longrange correlations developed in the volume during fracturing.

To characterize the topology of the fracture network within the serpentinite, we measured the spacing between fractures and reported the fracture spacing index, $N=H / S$, where $H$ is the thickness of the serpentinite layer and $S$ is the mean spacing between successive fractures (Price, 1966), as shown in the sketch of Figure 10. The value of the thickness-spacing index depends on rock type (Harris et al., 1960; Narr, 1991). We calculated the spacing index in seven representative horizontal cross sections located at different vertical positions above the solid base of the serpentinite cylinder at nine time steps (Figure S2). For both experiments, the value of $N$ increased during initiation of cracks in the serpentinite and stabilized at 50 min after the first fracture nucleated to values between 1 and 2 at the end of the experiment. For experiment Sp01, the $N$ ratio was slightly smaller because fewer fractures were generated after the initial fracturing event.

\subsection{Stress Distribution in the Serpentinite}

In series of 2-D linear elastic boundary element method models, increasing normal force exerted on the inner serpentinite wall captures the force of crystallization exerted (Figure 11). This suite of models provides two critical predictions that are consistent with our new and previous experiments (Zheng et al., 2018). When the normal stress exerted on the inner wall reaches a threshold value, $\sigma_{i}>30 \mathrm{MPa}$, the normal stress within the serpentinite, $\sigma_{\theta \theta}$, becomes tensile, consistent with Lamé's solution (Jaeger et al., 2007). When $\sigma_{i}$ is between 30 and $35 \mathrm{MPa}$, the magnitude of $\sigma_{\theta \theta}$ exceeds the tensile strength of serpentinite (10 MPa; e.g., Ague et al., 1998). Zheng et al. (2018) observed that reaction-induced fracturing produced a crystallization pressure of at least $30 \mathrm{MPa}$. This limit of $30 \mathrm{MPa}$ could arise in part from the visco-plastic strength of the porous material. If the material begins to compact and creep, the rate of reaction-induced fracturing may decrease (Skarbek et al., 2018). Our numerical models provide evidence that this value of the force of crystallization at the edge of the periclase/brucite core is sufficient to break the serpentinite.

The second critical prediction of these numerical models is that the highest tensile stresses will develop on the inner wall of the serpentinite (Figures 11e and 11f). Examination of the tomograms indicates that the first observable fractures nucleated near the periclase/brucite-serpentinite interface, consistent with the higher tensile stresses produced in these regions in the models. 


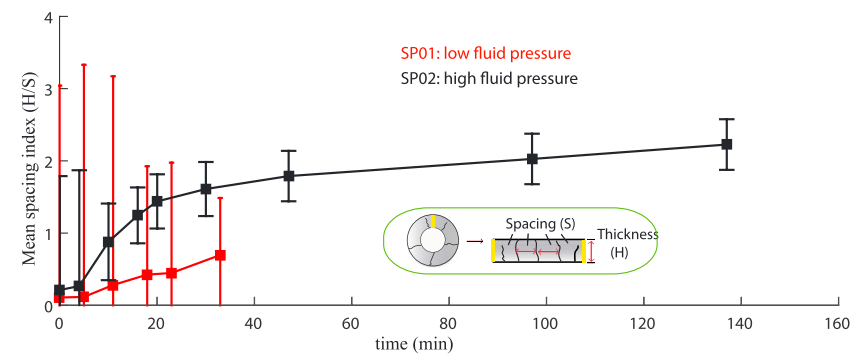

Figure 10. Evolution of mean fracture spacing index through time. The error bars show one standard deviation. (bottom inset) Sketch of the definition of the spacing index, $H / S$. Here the origin of time corresponds to 190 min for experiment Sp01 and 196 min for experiment Sp02 in the Figure 9. The space-time data of the fractures in the serpentinite for experiment Sp02 are shown in Figure S2.

\section{Discussion}

\subsection{Patterns of Reaction-Induced Fracturing}

In natural serpentinization, preexisting fracture networks provide fluid conduits for hydrating oceanic and upper mantle rocks. Olivine reacts with water to form serpentine, with a volume increase of $40-50 \%$. The hydration reaction of periclase to brucite investigated here is analogous to natural serpentinization. The microstructure in the periclase core during its transformation into brucite (Figure 12a) shows hierarchical patterns similar to the mesh structure of natural serpentinites (Figure 12b). The fracture patterns in the serpentinite samples in our experiments also appear similar to the patterns of veins and fracture networks observed in natural serpentinites (Figures 12c and 12d; see also Figure 5b in Andréani et al., 2007; Figure 4 in Rouméjon \& Cannat, 2014; and Figure 5 in Kelemen et al., 2018).

In our experiments, reaction-induced fractures in the serpentine samples were initiated perpendicular to the interface between the periclase core and the serpentine, forming a radial pattern (Figures 10 and 11a). Secondary fractures grow from these initial ones (Figures 7a and 8a). Such patterns have been described as resulting from a hierarchical fracturing process (Iyer et al., 2008; Jamtveit et al., 2009; Plümper et al., 2012). Existing fractures may exhibit dilatancy hardening behavior due to suction that increases the effective normal stress on the crack surfaces and promote the nucleation of new fractures (Ougier-Simonin \& Zhu, 2013; Rice, 1975).

Meanwhile, an increase in pore pressure increase tends to promote the tensile failure of a low porosity rock shaped as a hollow cylinder (Hubbert \& Willis, 1957; Schmitt \& Zoback, 1992). The higher fracturing rate at

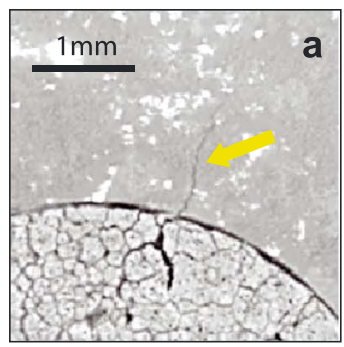

compression $>0$
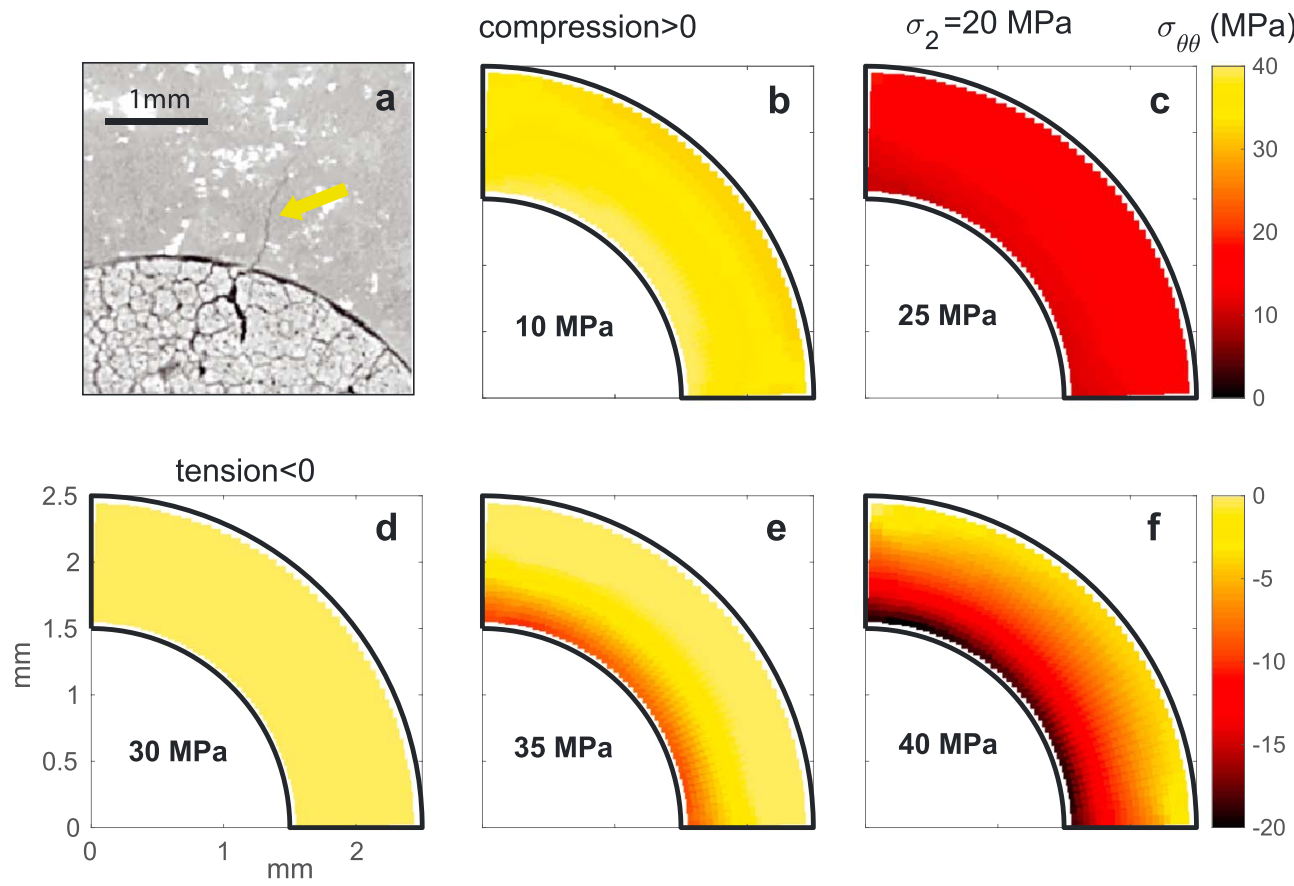

Figure 11. Investigation of the normal tangential stress distribution in the serpentinite. (a) Horizontal slice of the tomogram when we observe the first fracture (yellow arrow) in the serpentinite wall of experiment Sp02. (b-f) Normal tangential stress, $\sigma_{\theta \theta}$, distribution within horizontal slices of the serpentinite from 2-D linear elastic mechanical models. Increasing normal stress on the inner wall of the serpentinite: (b) 10, (c) 25, (d) 30, (e) 35, and (f) 40 MPa, with constant 20MPa confining stress on the outside wall. When the normal stress exerted on the inner wall, $\sigma_{i}$ is equal or larger than $30 \mathrm{MPa}, \sigma_{\theta \theta}$, becomes tensile (negative). The largest magnitudes of $\sigma_{\theta \theta}$ develop near the inner wall, representing the contact between the brucite/periclase and serpentinite, consistent with the observed nucleation of the earliest fractures at the inner wall (a). 

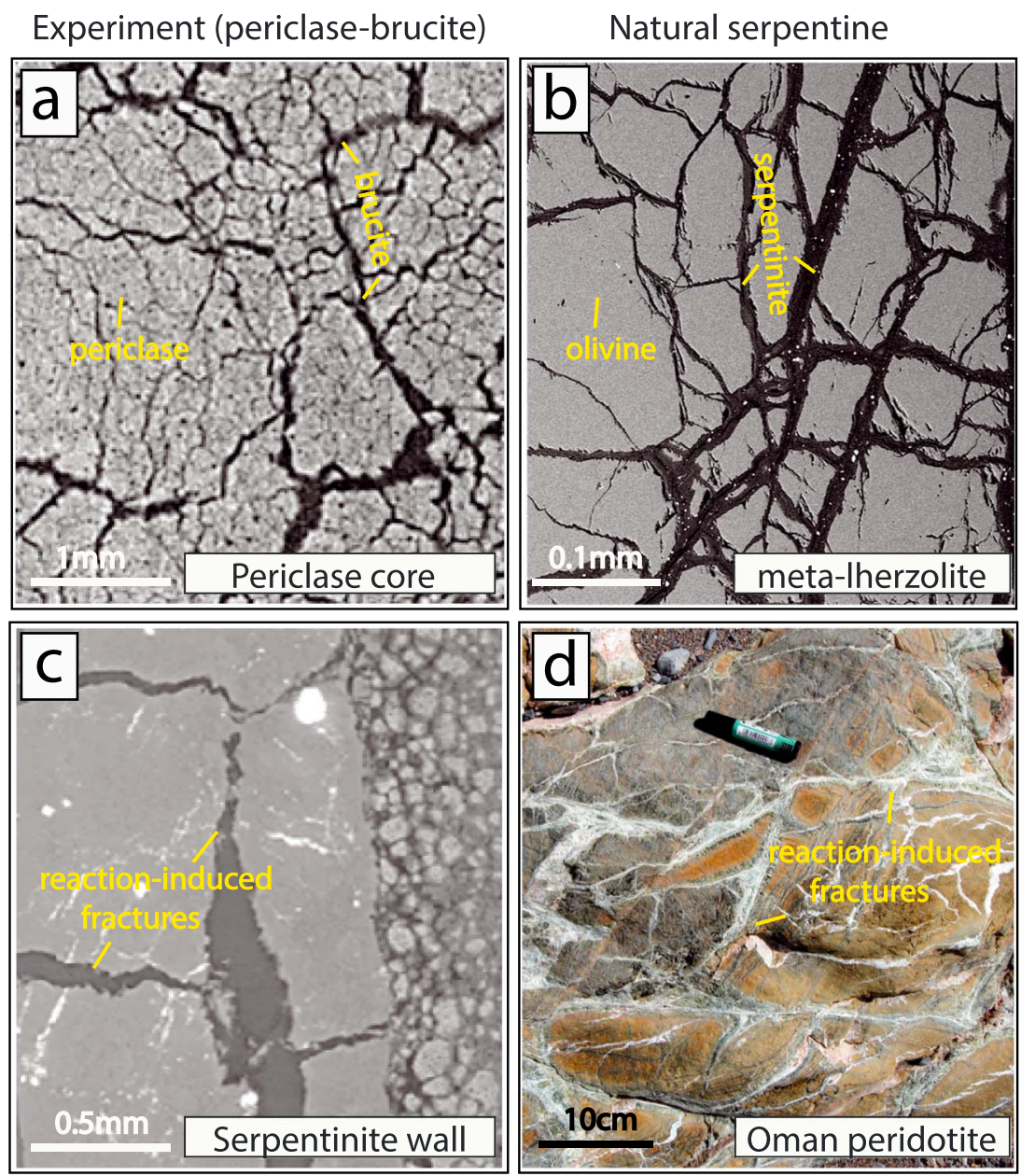

Figure 12. Comparison of experimental (a, c) and natural (b, d) observations. (a) Tomography image showing hydration reaction in the periclase in our experiment. (b) Mesh texture evolution during the replacement of olivine by serpentine in meta-dunite of a natural rock from Feragen, Norway. Image courtesy of Oliver Plümper (Plümper et al., 2014).

(c) Reaction-induced fracturing in the serpentinite in our experiment. (d) Veins of serpentinites produced by reactioninduced fracturing in peridotites from Oman. Image courtesy of Stéphane Guillot.

the initiation of the experiments could arise in part from the higher rate of pore pressure increase (Figure 10).

At the last stage of our experiment, the hydration reached $~ 50 \%$ completion (Figure 5). This degree of completion is consistent with observations of natural serpentinites collected in the Mid-Atlantic oceanic ridge, assuming that serpentinization occurred in a system conserving the mass of the initial minerals and open to fluids (Andréani et al., 2007). When the hydration degree is lower than 5\%, the fractures at the origin of veins are generally tensile cracks that formed between 4 - and 8-km depth in the mantle rock below the oceanic ridge (Andréani et al., 2007) or up to $30 \mathrm{~km}$ within the oceanic crust (Schlindwein \& Schmid, 2016). Andréani et al. (2007) suggest that serpentinization stopped at 50\% because in a closed system, the fluid pressure decreases as the fluid is consumed in the reaction. Complete serpentinization would therefore require that the system evolves from a closed stated to an open state. Fracture propagation would allow further fluid infiltration. The generation of new fractures in the periclase core slowed when the reaction degree was $20 \%$ (Figure 5). Rouméjon and Cannat (2014) observed that the reaction-induced fracturing process mainly occurred between $0 \%$ and $20 \%$ serpentinization in the Mid-Atlantic and Southwest Indian oceanic ridges. The plastic deformation of the weaker serpentine may enhance strain partitioning between the serpentine veins and olivine. Consequently, the rate of fracturing of the olivine may be reduced after $20 \%$ serpentinization. 
In experiment Sp01, the surface area of fractures was $0.8 \times 10^{-3} \mathrm{~m}^{2}$ at the end of the experiment. The volume of the serpentinite hosting the fractures was $1.1 \times 10^{-7} \mathrm{~m}^{3}$. Consequently, the reaction produced $7 \times 10^{3} \mathrm{~m}^{2}$ of fracture surface area per cubic meter of partially serpentinized rock. In experiment Sp02, the reaction produced $5.5 \times 10^{3} \mathrm{~m}^{2}$ of fracture surface area per cubic meter of partially serpentinized rock. These fractures create new reactive surfaces, increase the permeability, and allow fluid access, sustaining the hydration of peridotite.

The surface energy necessary to create these fractures is of the order of $6 \pm 1 \mathrm{~kJ} / \mathrm{m}^{3}$ of rock, assuming a surface energy of $1 \mathrm{~J} / \mathrm{m}^{2}$, an upper bound for minerals. Zheng et al. (2018) estimated that the Gibbs free energy for the periclase-brucite transformation could be as high as $25 \mathrm{~kJ} / \mathrm{mol}$ of periclase, corresponding to $2.2 \cdot 10^{9} \mathrm{~J} / \mathrm{m}^{3}$ of periclase when considering the molar volume of periclase of $11.248 \cdot 10^{-6} \mathrm{~m}^{3} / \mathrm{mol}^{\text {. This result }}$ suggests that the amount of strain energy converted to fracture energy in the serpentinite is negligible. Most of the thermodynamic energy was used as work against the confining pressure and heat dissipation during the experiments.

\subsection{Effect of Fluid Pressure on the Rate of Serpentinite Fracturing}

In our experiments, the hydration reaction from periclase to brucite broke the surrounding serpentinite. This reaction and subsequent fracturing produced a positive feedback loop between the hydration reaction and fracturing. The expansion of the periclase/brucite composite against the surrounding serpentinite exerted sufficient normal stress in the tangential direction to nucleate fractures at the inner wall of the serpentinite. These fractures then propagated radially outward and accommodated dilation and shear strain. As the fractures developed and accommodated strain, they increased the bulk porosity of the serpentinite, thereby increasing the reaction rate by channeling fresh fluid to unreacted surfaces.

The fracture spacing evolution of the two experiments follow similar trends: first high rates of decrease and then plateauing between 1 and 2 ratios of fracture spacing to layer thickness. However, the stabilization of the strain values occurred over a longer time period in experiment Sp02 (150 min) than Sp01 (15 min). The spatial distributions of the high incremental shear and dilative strains (Movies S3 and S4) indicate that the propagation of new fractures coincided with increases in the incremental strain magnitudes and that the continued opening of these fractures led to slower rates of strain accumulation (Figure 9). The higher pore pressure of experiment Sp02 (75 MPa) compared to experiment Sp01 (5 MPa) may have led to the longer period of strain rate increase and decrease in experiment Sp02 compared to experiment Sp01. Increasing pore pressure can reduce the brittle strength and influence slip instability (Ougier-Simonin \& Zhu, 2013, 2015). At the same effective pressure, fracture propagation in antigorite serpentine samples is considerably slower at high pore fluid pressures (French \& Zhu, 2017), similar to what is observed in our experiments.

\subsection{Implications of Reaction-Induced Fracture Development}

Serpentinization may induce strain localization and intermediate-depth seismicity (Hacker et al., 2003; Raleigh \& Paterson, 1965). Schlindwein and Schmid (2016) proposed that the microseismicity observed in the South-West Indian mid-oceanic slow spreading ridge was related to active serpentinization and that reaction-induced fractures could produce shear failure up to depths of $20 \mathrm{~km}$. Consistent with these observations, our DVC analyses reveal concentrations of Von Mises incremental strain values, indicative of shear strain. The serpentinite samples may have failed initially as mode I cracks hosting tension. However, these fractures then hosted localized concentrations of shear strain, indicating that stress redistribution during reaction-induced fracturing can induce slip along preexisting defects. This observation supports interpretations that microseismicity measured at slow-spreading ridges may arise from active serpentinization of the oceanic crust (Horning et al., 2018). This observation also underscores the prevalence of mixed-mode deformation and the often false dichotomy of shear and tensile failure and deformation.

Earthquakes are not uniformly distributed in magnitude. Instead, the distribution of earthquake magnitude obeys a power law, known as the Gutenberg-Richter magnitude-frequency relation. For worldwide seismicity, the power law exponent $b$ value is close to 1.0. However, higher $b$ values have been observed in geothermal systems with local injections of fluids under high confining pressure (Bachmann et al., 2012). The $b$ values along convergent plate margins undergoing fluid production by dehydration reactions show also higher $b$ values in the range of 1.3 to 1.6 (Singh \& Singh, 2015; Wiemer \& Benoit, 1996). 
We compare the statistics of strain distribution calculated using DVC in our experiments with the statistics of earthquake magnitudes observed in the crust. The Gutenberg-Richter magnitude-frequency relation can be expressed in seismic moment $M_{0}$, where the log-log plot of the cumulated number of earthquakes versus seismic moment is a straight line with a negative slope $\beta \sim 2 / 3 b$ (eqs. 6.6 and 7.2b in Ben-Zion et al., 2003). The seismic moment is defined by $M_{0}=G A d$, where $G$ is the shear modulus of the rock, $A$ is the rupture area, and $d$ is the slip distance. In our DVC calculation, the surface area, A, is proportional to the square of the correlation window size, $L$ if one considers that the shear strain is due to the slip of a small fault that cuts the entire correlation window. The shear strain, $\varepsilon_{\mathrm{vM}}$, we calculate is related to a slip distance, $d$, and the size of the correlation window, $L$, such that $\varepsilon_{\mathrm{vM}}=d / L$. As a consequence, the relationship between the von Mises strain, $\varepsilon_{\mathrm{vM}}$, and the seismic moment can be approximated $M_{0}=G L^{3} \varepsilon_{\mathrm{vM}}$, and the shear strain we measured using DVC is therefore proportional to $M_{0}$. We found that the magnitude distribution of the shear strain in the experiments follows a power law relationship (Figure 9c) with a slope $\alpha=-3.0$ in a log-log plot of the frequency-moment distribution (eq. 7.1a in Ben-Zion et al., 2003), corresponding to a slope $\alpha+1=-2.0$ for a cumulated distribution (eq. 7.1b in Ben-Zion et al., 2003). Making an analogy with the GutenbergRichter law, our experimental law shows a power law exponent $\alpha+1=2 / 3 b$. This power law exponent corresponds to a value of $b=3.0$ and $\beta=2.0$. We interpret this power law relationship as a manifestation of the elastic stress interactions in the serpentinite during deformation. Long-range elastic interactions play a key role during the failure of heterogeneous materials because heterogeneities may concentrate stress and reduce the overall material strength (e.g., Vasseur et al., 2015). The presence of heterogeneities may also change the relative size distribution of seismic events, represented by the $b$ value, to a larger proportion of small earthquakes (Scholz, 1968). The range of the strain data is limited at just over one order of magnitude. At the lower range, our strain data are limited by the imaging resolution; and at the higher range, the data are limited by the parameters of the DVC calculation, including the correlation window size and node size. While $\beta \sim 2 / 3$ for earthquakes, the exponent of the power law of the shear strain magnitude distributions throughout each experiment is $\beta \sim 2.0$. Whereas the $\beta$ value represents only the radiated seismic energy for earthquakes, the exponent of the strain magnitude distribution in our experiments represents the total shear strain energy. One plausible explanation of the larger exponent of strain magnitude distribution in our

\section{Acknowledgments}

The deformation apparatus was built by Sanchez Technology. This study received funding from the Norwegian Research Council (project HADES, grant 250661 to F. R.) and the European Union (669972, "Disequilibrium Metamorphism" to B. J.). Beamtime was allocated at the European Synchrotron Radiation Facility (Long Term Proposal ES-295), and we thank Alexander Rack and Paul Tafforeau for the technical support. Data storage was provided by UNINETT Sigma2 - the National Infrastructure for High Performance Computing and Data Storage in Norway (project NS9073K). W. Z. was partially supported by the U. S. National Science Foundation through EAR-1761912. The authors thank Oliver Plümper for providing image 12b, Stéphane Guillot for providing image 12, and Claire Aupart for helpful suggestions. We thank Douglas Schmitt, Holger Stunitz, and Peter Kelemen who provided constructive reviews that helped improve the article. The X-ray tomography data (series of 3D volumes and 16-bytes gray scale) supporting the conclusions are available on the National Norwegian data repository center (https://doi.org/ 10.11582/2018.00037). The boundary element numerical code Fric2D is available as part of the GROW package tools on GitHub (https://github.com/ mlcooke/GROW). experiments (i.e., $\beta=2.0$ ) could be that strain events are aseismic.

\section{Conclusions}

The hydration of periclase into brucite generated enough stress to break the confining serpentinite cylinder. Our numerical modeling results indicate that the effective force of crystallization reached a magnitude of at least $30 \mathrm{MPa}$, consistent with previous experimental results (Zheng et al., 2018). The rate of fracture development at 5-MPa pore fluid pressure and 45-MPa differential stress was higher than that at 75-MPa fluid pressure and 1-MPa differential stress, implying that fracture growth is sensitive to hydromechanical feedbacks. The fractures nucleated by the hydration reaction are mixed-mode, including both tensile and shear components. The magnitude distribution of the shear strain (i.e., von Mises strain) follows a power law relationship over one order of strain magnitude, indicating the existence of long-range elastic interactions. These results provide experimental support that microseismicity may result from the serpentinization of deep oceanic crust at slow-spreading ridges.

\section{References}

Ague, J., Park, J., \& Rye, D. (1998). Regional metamorphic dehydration and seismic hazard. Geophysical Research Letters, 25 (22), $4221-4224$. https://doi.org/10.1029/1998GL900124

Andreani, M., Luquot, L., Gouze, P., Godard, M., Hoise, E., \& Gibert, B. (2009). Experimental study of carbon sequestration reactions controlled by the percolation of $\mathrm{CO}_{2}$-rich brine through peridotites. Environmental Science \& Technology, 43(4), 1226-1231. https://doi. org/10.1021/es8018429

Andréani, M., Mével, C., Boullier, A. M., \& Escartin, J. (2007). Dynamic control on serpentine crystallization in veins: Constraints on hydration processes in oceanic peridotites. Geochemistry, Geophysics, Geosystems, 8, Q02012. https://doi.org/10.1029/2006GC001373 Bachmann, C. E., Wiemer, S., Goertz-Allmann, B., \& Woessner, J. (2012). Influence of pore-pressure on the event-size distribution of induced earthquakes. Geophysical Research Letters, 39, L09302. https://doi.org/10.1029/2012GL051480

Bay, B. K., Smith, T. S., Fyhrie, D. P., \& Saad, M. (1999). Digital volume correlation: Three-dimensional strain mapping using X-ray tomography. Experimental Mechanics, 39(3), 217-226. https://doi.org/10.1007/BF02323555

Beinlich, A., Plümper, O., Hövelmann, J., Austrheim, H., \& Jamtveit, B. (2012). Massive serpentinite carbonation at Linnajavri, N-Norway. Terra Nova, 24(6), 446-455. https://doi.org/10.1111/j.1365-3121.2012.01083.x 
Ben-Zion, Y., Lee, W. H. K., Kanamori, H., Jennings, P. C., \& Kisslinger, C. (2003). Key formulas in earthquake seismology. In W. H., Lee, P., Jennings, C., Kisslinger, \& H., Kanamori (Eds.), International handbook of earthquake \& engineering seismology (pp. 1857-1875). London: Academic Press, Elsevier.

Buades, A., Coll, B., \& Morel, J.-M. (2005). A non-local algorithm for image denoising. Paper presented at the Computer Society Conference on Computer Vision and Pattern Recognition, 2005. IEEE.

Clauset, A., Shalizi, C. R., \& Newman, M. E. (2009). Power-law distributions in empirical data. SIAM Review, 51(4), 661-703. https://doi. org/10.1137/070710111

Cooke, M., \& Pollard, D. (1997). Bedding-plane slip in initial stages of fault-related folding. Journal of Structural Geology, 19(3-4), 567-581. https://doi.org/10.1016/S0191-8141(96)00097-1

Escartin, J., Hirth, G., \& Evans, B. (1997). Effects of serpentinization on the lithospheric strength and the style of normal faulting at slowspreading ridges. Earth and Planetary Science Letters, 151(3-4), 181-189. https://doi.org/10.1016/S0012-821X(97)81847-X

French, M. E., \& Zhu, W. (2017). Slow fault propagation in serpentinite under conditions of high pore fluid pressure. Earth and Planetary Science Letters, 473, 131-140. https://doi.org/10.1016/j.epsl.2017.06.009

Gratier, J.-P., Frery, E., Deschamps, P., Røyne, A., Renard, F., Dysthe, D., \& Hamelin, B. (2012). How travertine veins grow from top to bottom and lift the rocks above them: The effect of crystallization force. Geology, 40(11), 1015-1018. https://doi.org/10.1130/G33286.1

Guillot, S., Schwartz, S., Reynard, B., Agard, P., \& Prigent, C. (2015). Tectonic significance of serpentinites. Tectonophysics, 646, 1-19. https://doi.org/10.1016/j.tecto.2015.01.020

Hacker, B. R., Abers, G. A., \& Peacock, S. M. (2003). Subduction factory 1 . Theoretical mineralogy, densities, seismic wave speeds, and $\mathrm{H}_{2} \mathrm{O}$ contents. Journal of Geophysical Research, 108(B1), 2029. https://doi.org/10.1029/2001JB001127

Hall, S. A., Bornert, M., Desrues, J., Pannier, Y., Lenoir, N., Viggiani, G., \& Bésuelle, P. (2010). Discrete and continuum analysis of localised deformation in sand using X-ray [mu] CT and volumetric digital image correlation. Géotechnique, 60(5), 315-322. https://doi.org/ 10.1680/geot.2010.60.5.315

Harris, J. F., Taylor, G. L., \& Walper, J. L. (1960). Relation of deformational fractures in sedimentary rocks to regional and local structure. AAPG Bulletin, 44(12), 1853-1873.

Hirth, G., \& Guillot, S. (2013). Rheology and tectonic significance of serpentinite. Elements, 9(2), 107-113. https://doi.org/10.2113/ gselements.9.2.107

Horning, G., Sohn, R. A., Canales, J. P., \& Dunn, R. A. (2018). Local seismicity of the rainbow massif on the Mid-Atlantic Ridge. Journal of Geophysical Research: Solid Earth, 123, 1615-1630. https://doi.org/10.1002/2017JB015288

Hubbert, M. K., \& Willis, D. G. (1957). Mechanics of hydraulic fracturing. Transactions of the American Institute of Mining and Metallurgical Engineers, 210, 153-168.

Iyer, K., Jamtveit, B., Mathiesen, J., Malthe-Sørenssen, A., \& Feder, J. (2008). Reaction-assisted hierarchical fracturing during serpentinization. Earth and Planetary Science Letters, 267(3-4), 503-516. https://doi.org/10.1016/j.epsl.2007.11.060

Jaeger, J., Cook, N. G., \& Zimmerman, R. W. (2007). Fundamentals of rock mechanics (4th ed.). New York: Wiley.

Jamtveit, B., Malthe-Sørenssen, A., \& Kostenko, O. (2008). Reaction enhanced permeability during retrogressive metamorphism. Earth and Planetary Science Letters, 267(3-4), 620-627. https://doi.org/10.1016/j.epsl.2007.12.016

Jamtveit, B., Putnis, C. V., \& Malthe-Sørenssen, A. (2009). Reaction induced fracturing during replacement processes. Contributions to Mineralogy and Petrology, 157(1), 127-133. https://doi.org/10.1007/s00410-008-0324-y

Kelemen, P. B., Aines, R., Bennett, E., Benson, S. M., Carter, E., Coggon, J. A., \& Godard, M. (2018). In situ carbon mineralization in ultramafic rocks: Natural processes and possible engineered methods. Energy Procedia, 146, 92-102. https://doi.org/10.1016/j. egypro.2018.07.013

Kelemen, P. B., \& Hirth, G. (2012). Reaction-driven cracking during retrograde metamorphism: Olivine hydration and carbonation. Earth and Planetary Science Letters, 345, 81-89.

Kelemen, P. B., \& Matter, J. (2008). In situ carbonation of peridotite for $\mathrm{CO}_{2}$ storage. Proceedings of the National Academy of Sciences, 105(45), 17,295-17,300. https://doi.org/10.1073/pnas.0805794105

Kuleci, H., Schmidt, C., Rybacki, E., Petrishcheva, E., \& Abart, R. (2016). Hydration of periclase at $350{ }^{\circ} \mathrm{C}$ to $620^{\circ} \mathrm{C}$ and $200 \mathrm{MPa}$ Experimental calibration of reaction rate. Mineralogy and Petrology, 110(1), 1-10. https://doi.org/10.1007/s00710-015-0414-2

Lafay, R., Montes-Hernandez, G., \& Renard, F. (2018). Experimental evidence of reaction-induced micro-cracking and vein patterning during serpentinization of olivine. Minerals, 8(9), 412. https://doi.org/10.3390/min8090412

Lambart, S., Savage, H. M., Robinson, B. G., \& Kelemen, P. B. (2018). Experimental investigation of the pressure of crystallization of $\mathrm{Ca}(\mathrm{OH})_{2}$ : Implications for the reactive cracking process. Geochemistry, Geophysics, Geosystems, 19, 3448-3458. https://doi.org/10.1029/ 2018GC007609

Lisabeth, H., Zhu, W., Kelemen, P., \& Ilgen, A. (2017). Experimental evidence for chemo-mechanical coupling during carbon mineralization in ultramafic rocks. Earth and Planetary Science Letters, 474, 355-367. https://doi.org/10.1016/j.epsl.2017.06.045

Louis, L., Wong, T.-F., \& Baud, P. (2007). Imaging strain localization by X-ray radiography and digital image correlation: Deformation bands in Rothbach sandstone. Journal of Structural Geology, 29(1), 129-140. https://doi.org/10.1016/j.jsg.2006.07.015

Macdonald, A., \& Fyfe, W. (1985). Rate of serpentinization in seafloor environments. Tectonophysics, 116(1-2), 123-135. https://doi.org/ 10.1016/0040-1951(85)90225-2

Malvoisin, B., Brantut, N., \& Kaczmarek, M.-A. (2017). Control of serpentinisation rate by reaction-induced cracking. Earth and Planetary Science Letters, 476, 143-152. https://doi.org/10.1016/j.epsl.2017.07.042

Malvoisin, B., Brunet, F., Carlut, J., Rouméjon, S., \& Cannat, M. (2012). Serpentinization of oceanic peridotites: 2. Kinetics and processes of San Carlos olivine hydrothermal alteration. Journal of Geophysical Research, 117, B04102. https://doi.org/10.1029/ 2011JB008842

McBeck, J., Kobchenko, M., Hall, S. A., Tudisco, E., Cordonnier, B., Meakin, P., \& Renard, F. (2018). Investigating the onset of strain localization within anisotropic shale using digital volume correlation of time-resolved X-ray microtomography images. Journal of Geophysical Research: Solid Earth, 123, 7509-7528. https://doi.org/10.1029/2018JB015676

Narr, W. (1991). Fracture density in the deep subsurface: Techniques with application to point Arguello oil field (1). AAPG Bulletin, 75(8), $1300-1323$.

Njiekak, G., Schmitt, D. R., \& Kofman, R. S. (2018). Pore systems in carbonate formations, Weyburn field, Saskatchewan, Canada: Microtomography, helium porosimetry and mercury intrusion porosimetry characterization. Journal of Petroleum Science and Engineering, 171, 1496-1513. https://doi.org/10.1016/j.petrol.2018.08.029

Noiriel, C., Renard, F., Doan, M.-L., \& Gratier, J.-P. (2010). Intense fracturing and fracture sealing induced by mineral growth in porous rocks. Chemical Geology, 269(3-4), 197-209. https://doi.org/10.1016/j.chemgeo.2009.09.018 
O'Hanley, D. S. (1992). Solution to the volume problem in serpentinization. Geology, 20(8), 705-708. https://doi.org/10.1130/00917613(1992)020<0705:STTVPI >2.3.CO;2

O'Hanley, D. S. (1996). Serpentinites: Records of tectonic and petrological history (p. 277). New York: Oxford University Press.

Ougier-Simonin, A., \& Zhu, W. (2013). Effects of pore fluid pressure on slip behaviors: An experimental study. Geophysical Research Letters, 40, 2619-2624. https://doi.org/10.1002/grl.50543

Ougier-Simonin, A., \& Zhu, W. (2015). Effect of pore pressure buildup on slowness of rupture propagation. Journal of Geophysical Research: Solid Earth, 120, 7966-7985. https://doi.org/10.1002/2015JB012047

Peuble, S., Andreani, M., Godard, M., Gouze, P., Barou, F., Van de Moortele, B., et al. (2015). Carbonate mineralization in percolated olivine aggregates: Linking effects of crystallographic orientation and fluid flow. American Mineralogist, 100(2-3), 474-482. https://doi.org/ 10.2138/am-2015-4913

Plümper, O., Beinlich, A., Bach, W., Janots, E., \& Austrheim, H. (2014). Garnets within geode-like serpentinite veins: Implications for element transport, hydrogen production and life-supporting environment formation. Geochimica et Cosmochimica Acta, 141, 454-471. https://doi.org/10.1016/j.gca.2014.07.002

Plümper, O., Røyne, A., Magrasó, A., \& Jamtveit, B. (2012). The interface-scale mechanism of reaction-induced fracturing during serpentinization. Geology, 40(12), 1103-1106. https://doi.org/10.1130/G33390.1

Price, N. J. (1966). Fault and joint development in brittle and semi-brittle rock. London: Pergamon.

Raleigh, C. B., \& Paterson, M. (1965). Experimental deformation of serpentinite and its tectonic implications. Journal of Geophysical Research, 70(16), 3965-3985. https://doi.org/10.1029/JZ070i016p03965

Renard, F., Cordonnier, B., Dysthe, D. K., Boller, E., Tafforeau, P., \& Rack, A. (2016). A deformation rig for synchrotron microtomography studies of geomaterials under conditions down to $10 \mathrm{~km}$ depth in the Earth. Journal of Synchrotron Radiation, 23(4), 1030-1034. https:// doi.org/10.1107/S1600577516008730

Renard, F., McBeck, J., Cordonnier, B., Zheng, X., Kandula, N., Sanchez, J. R., et al. (2018). Dynamic in situ three-dimensional imaging and digital volume correlation reveal strain localization and fracture coalescence in sandstone. Pure and Applied Geophysics. https://doi.org/ 10.1007/s00024-018-2003-x

Rice, J. R. (1975). On the stability of dilatant hardening for saturated rock masses. Journal of Geophysical Research, 80(11), $1531-1536$. https://doi.org/10.1029/JB080i011p01531

Rouméjon, S., \& Cannat, M. (2014). Serpentinization of mantle-derived peridotites at mid-ocean ridges: Mesh texture development in the context of tectonic exhumation. Geochemistry, Geophysics, Geosystems, 15, 2354-2379. https://doi.org/10.1002/2013GC005148

Rouméjon, S., Cannat, M., Agrinier, P., Godard, M., \& Andreani, M. (2015). Serpentinization and fluid pathways in tectonically exhumed peridotites from the Southwest Indian Ridge (62-65 E). Journal of Petrology, 56(4), 703-734. https://doi.org/10.1093/petrology/egv014

Rudge, J. F., Kelemen, P. B., \& Spiegelman, M. (2010). A simple model of reaction-induced cracking applied to serpentinization and carbonation of peridotite. Earth and Planetary Science Letters, 291(1-4), 215-227. https://doi.org/10.1016/j.epsl.2010.01.016

Scherer, G. W. (2004). Stress from crystallization of salt. Cement and Concrete Research, 34(9), 1613-1624. https://doi.org/10.1016/j. cemconres.2003.12.034

Schlindwein, V., \& Schmid, F. (2016). Mid-ocean-ridge seismicity reveals extreme types of ocean lithosphere. Nature, 535(7611), 276-279. https://doi.org/10.1038/nature18277

Schmitt, D. R., \& Zoback, M. D. (1992). Diminished pore pressure in low-porosity crystalline rock under tensional failure: Apparent strengthening by dilatancy. Journal of Geophysical Research, 97(B1), 273-288. https://doi.org/10.1029/91JB02256

Scholz, C. H. (1968). The frequency-magnitude relation of microfracturing in rock and its relation to earthquakes. Bulletin of the Seismological Society of America, 58, 399-415.

Singh, C., \& Singh, S. (2015). Imaging $b$-value variation beneath the Pamir-Hindu Kush region. Bulletin of the Seismological Society of America, 105(2A), 808-815. https://doi.org/10.1785/0120140112

Skarbek, R. M., Savage, H. M., Kelemen, P. B., \& Yancopoulos, D. (2018). Competition between crystallization-induced expansion and creep compaction during gypsum formation, and implications for serpentinization. Journal of Geophysical Research: Solid Earth, 123, 5372-5393. https://doi.org/10.1029/2017JB015369

Song, I., Suh, M., Woo, Y.-K., \& Hao, T. (2004). Determination of the elastic modulus set of foliated rocks from ultrasonic velocity measurements. Engineering Geology, 72(3-4), 293-308. https://doi.org/10.1016/j.enggeo.2003.10.003

Tudisco, E., Andò, E., Cailletaud, R., \& Hall, S. A. (2017). TomoWarp2: A local digital volume correlation code. SoftwareX, 6, 267-270. https://doi.org/10.1016/j.softx.2017.10.002

Tudisco, E., Hall, S., Charalamp idou, E., Kardjilov, N., Hilger, A., \& Sone, H. (2015). Full field measurements of strain localisation in sandstone by neutron tomography and 3D volumetric digital image correlation. Physics Procedia, 69, 509-515. https://doi.org/10.1016/j. phpro.2015.07.072

Tutolo, B. M., Mildner, D. F., Gagnon, C. V., Saar, M. O., \& Seyfried, W. E. Jr. (2016). Nanoscale constraints on porosity generation and fluid flow during serpentinization. Geology, 44(2), 103-106. https://doi.org/10.1130/G37349.1

Ulven, O., Jamtveit, B., \& Malthe-Sørenssen, A. (2014). Reaction-driven fracturing of porous rock. Journal of Geophysical Research: Solid Earth, 119, 7473-7486. https://doi.org/10.1002/2014JB011102

Van Noort, R., Wolterbeek, T., Drury, M., Kandianis, M., \& Spiers, C. (2017). The force of crystallization and fracture propagation during insitu carbonation of peridotite. Minerals, 7(10), 190. https://doi.org/10.3390/min7100190

Vasseur, J., Wadsworth, F. B., Lavallée, Y., Bell, A. F., Main, I. G., \& Dingwell, D. B. (2015). Heterogeneity: The key to failure forecasting. Scientific Reports, 5(1), 13259. https://doi.org/10.1038/srep13259

Viggiani, G., Lenoir, N., Bésuelle, P., Di Michiel, M., Marello, S., Desrues, J., \& Kretzschmer, M. (2004). X-ray microtomography for studying localized deformation in fine-grained geomaterials under triaxial compression. Comptes rendus Mécanique, 332(10), 819-826. https://doi.org/10.1016/j.crme.2004.05.006

Wiemer, S., \& Benoit, J. P. (1996). Mapping the $b$-value anomaly at $100 \mathrm{~km}$ depth in the Alaska and New Zealand subduction zones. Geophysical Research Letters, 23(13), 1557-1560. https://doi.org/10.1029/96GL01233

Xing, T., Zhu, W., Fusseis, F., \& Harrison, L. (2018). Generating porosity during olivine carbonation via dissolution channels and expansion cracks. Solid Earth, 9(4), 879-896. https://doi.org/10.5194/se-9-879-2018

Zheng, X., Cordonnier, B., Zhu, W., Renard, F., \& Jamtveit, B. (2018). Effects of confinement on reaction-induced fracturing during hydration of periclase. Geochemistry, Geophysics, Geosystems, 19, 2661-2672. https://doi.org/10.1029/2017GC007322

Zhu, W., Fusseis, F., Lisabeth, H., Xing, T., Xiao, X., De Andrade, V., \& Karato, S. i. (2016). Experimental evidence of reaction-induced fracturing during olivine carbonation. Geophysical Research Letters, 43, 9535-9543. https://doi.org/10.1002/2016GL070834 